\title{
Influenza A(H3N2) Virus in Swine at Agricultural Fairs and Transmission to Humans, Michigan and Ohio, USA, 2016
}

\author{
Andrew S. Bowman, Rasna R. Walia, \\ Jacqueline M. Nolting, Amy L. Vincent, \\ Mary Lea Killian, Michele M. Zentkovich, \\ Joshua N. Lorbach, Sarah E. Lauterbach, \\ Tavis K. Anderson, C. Todd Davis, \\ Natosha Zanders, Joyce Jones, Yunho Jang, \\ Brian Lynch, Marisela R. Rodriguez, \\ Lenee Blanton, Stephen E. Lindstrom, \\ David E. Wentworth, John Schiltz, \\ James J. Averill, Tony Forshey
}

In 2016, a total of 18 human infections with influenza $A(H 3 N 2)$ virus occurred after exposure to influenza-infected swine at 7 agricultural fairs. Sixteen of these cases were the result of infection by a reassorted virus with increasing prevalence among US swine containing a hemagglutinin gene from 2010-11 human seasonal H3N2 strains.

$I^{n}$ nfluenza A virus infects many animal species. Zoonotic transmission allows for the introduction of novel influenza A virus strains to the human population, which has the potential to cause the next influenza pandemic. Swine exhibitions at agricultural fairs have emerged as a source for amplification of swine-lineage influenza A virus; these unique swine-human interfaces have generated most human infections with variant influenza $\mathrm{A}$ virus in the United States (1).

During July-August 2016, outbreaks of variant H3N2 virus $(\mathrm{H} 3 \mathrm{~N} 2 \mathrm{v})$ were reported in Ohio and Michigan, and 18 zoonotic influenza A virus infections were detected (2). All persons identified with H3N2v infections during these outbreaks reported swine exposure while attending $\geq 1$ of 7 fairs in Ohio or Michigan. We examined the role of

Author affiliations: The Ohio State University, Columbus, Ohio, USA (A.S. Bowman, J.M. Nolting, M.M. Zentkovich, J.N. Lorbach,

S.E. Lauterbach); US Department of Agriculture, Ames, lowa, USA (R.R. Walia, A.L. Vincent, M.L. Killian, T.K. Anderson, J. Schiltz); Centers for Disease Control and Prevention, Atlanta, Georgia, USA (C.T. Davis, N. Zanders, J. Jones, Y. Jang, B. Lynch, M.R. Rodriguez, L. Blanton, S.E. Lindstrom, D.E. Wentworth); Michigan Department of Agriculture and Rural Development, Lansing, Michigan, USA (J.J. Averill); Ohio Department of Agriculture, Reynoldsburg, Ohio (T. Forshey)

DOI: https://doi.org/10.3201/eid2309.170847 exhibition swine in the transmission of this reassortant influenza A virus, which contained a hemagglutinin gene from 2010-11 human seasonal H3N2 strains.

\section{The Study}

Active influenza A virus surveillance among exhibition swine occurred during summer 2016 at 101 agricultural fairs across the midwestern United States; pigs were sampled at the end of exhibition irrespective of clinical signs of respiratory disease (3). Samples obtained using nasal swabs or nasal wipes were stored in viral transport medium at $-80^{\circ} \mathrm{C}(4,5)$. Upon notification from the state animal health official, samples collected from pigs at fairs associated with $\mathrm{H} 3 \mathrm{~N} 2 \mathrm{v}$ cases were screened for influenza A virus with real-time reverse transcription PCR, and positive samples were inoculated for virus isolation as previously described (6). The genomes of 1 or 2 isolates per fair were sequenced, and the nucleotide sequences were deposited into GenBank (7). Nucleotide sequences of the $\mathrm{H} 3 \mathrm{~N} 2 \mathrm{v}$ viruses detected in humans were deposited in the GISAID database (online Technical Appendix, https://wwwnc.cdc.gov/EID/article/23/9/170847-Techapp.pdf).

We used MAFFT version 7.222 (8) to align sequences and manually corrected them in MEGA7 (9). We inferred maximum-likelihood trees by using IQ-TREE version 1.4.3 under a general time reversible plus gamma distribution plus invariant sites evolutionary model (10), and assessed branch support using an ultrafast bootstrap approximation with 1,000 replicates (11). We visualized and annotated trees using MEGA7.

We found that 7 fairs in Ohio $(\mathrm{n}=4)$ and Michigan $(\mathrm{n}=3)$ were associated with human H3N2v cases during July-August 2016. Of those, 6 (fairs A-F) were participating in the active influenza A virus swine surveillance program. We also included a diagnostic lab submission for a pig with respiratory disease at the seventh fair (fair $G$ ) in this study.

We sampled 161 pigs across the 7 fairs, and isolated $\mathrm{H} 3 \mathrm{~N} 2$ virus from $\geq 1$ pig at each fair. Virus isolation data from fairs A-F (Table 1) indicated that the average prevalence of influenza A-infected swine in these fairs was $77.5 \%$ (individual fair range $60 \%-90 \%$ ), indicating extensive influenza A virus amplification within the swine at each of these fairs. However, widespread influenza-like 
Table 1. Influenza A virus $\mathrm{rRT}-\mathrm{PCR}$ and virus isolation test results of samples from active surveillance among swine at agricultural fairs, Michigan and Ohio, USA, 2016*

\begin{tabular}{lcccc}
\hline & ILI among swine & No. swine & \multicolumn{2}{c}{ No. (\%) positive } \\
\cline { 3 - 5 } Fair & reported & sampled & rRT-PCR & Isolation \\
\hline A & Yes & 20 & $20(100)$ & $18(90)$ \\
B & No & 20 & $17(85)$ & $17(85)$ \\
C & No & 20 & $20(100)$ & $18(90)$ \\
D & No & 20 & $18(90)$ & $14(70)$ \\
E & Yes & 20 & $20(100)$ & $18(90)$ \\
F & No & 20 & $15(75)$ & $12(60)$ \\
\hline
\end{tabular}

*Nasal swab or nasal wipe samples were collected from swine at the end of the fair. ILI, influenza-like illness; rRT-PCR, real-time reverse transcription PCR

illness among swine was reported at only 2 of the fairs (fairs A and E), suggesting that subclinical influenza A infections in pigs remain a threat to public health (3).

A fair-by-fair comparison of the influenza A virus genomes sequenced from human $\mathrm{H} 3 \mathrm{~N} 2 \mathrm{v}$ cases and isolates from swine provided strong molecular evidence of zoonotic influenza A virus transmission. The viruses recovered from swine were nearly identical to viruses identified in humans, and human virus gene segment sequences were nested within monophyletic swine virus clades. We identified 2 distinct $\mathrm{H} 3$ lineages in the pigs and humans across the implicated fairs (Figure 1). An influenza A virus from the well-established $\mathrm{H} 3$ cluster IV-A, found in the pigs at fair $\mathrm{C}$, was responsible for $2(11.1 \%)$ human cases. This cluster IV-A H3N2 genome belonged to the previously described $\mathrm{H} 3$ genotype 1 (Table 2) and was similar to the viruses responsible for the $\mathrm{H} 3 \mathrm{~N} 2 \mathrm{v}$ infections detected in 2011-2013 (12). The influenza A virus detected in swine at the 6 fairs associated with the remaining $16(88.9 \%)$ human $\mathrm{H} 3 \mathrm{~N} 2 \mathrm{v}$ cases was a relatively new $\mathrm{H} 3$ lineage in swine. The HA gene of this virus descended from the human seasonal H3N2 virus circulating in 2010-11, which has since reassorted with enzootic swine influenza A viruses to produce novel viruses in the US swine herd (13). The other 7 gene segments in this human-like $\mathrm{H} 3$ reassortant virus were of the same lineages as those segments found in the cluster IV-A virus (Table 2).

Irrespective of the fair of origin, the genomic sequences of all 11 human-like H3N2 virus isolates from swine were $\geq 99.89 \%$ identical to each other, demonstrating clonal expansion of 1 virus across 2 states. This pattern of virus dissemination within the exhibition swine population was a hallmark of the 2012 fair season, when 306 H3N2v human cases were reported ( 6 ).

Influenza A virus was detected in pigs at each fair at least 1 day before each $\mathrm{H} 3 \mathrm{~N} 2 \mathrm{v}$ virus infection was detected in humans (Figure 2). The observed lag time between the collection of human and swine samples is probably a function of the timing for active surveillance in swine (i.e., swine are sampled at the end of the fair), whereas specimens were collected from humans when they showed symptoms of influenza-like illness (Figure 2). Retrospective investigations of infections in the swine from these fairs would not have been possible if the pig sampling relied on protocols triggered by the detection of $\mathrm{H} 3 \mathrm{~N} 2 \mathrm{v}$ virus cases in humans because fairs typically run for 1 week and infected swine would have been dispersed before sampling could have occurred.

\section{Conclusions}

Variant influenza infections in humans continue to occur through contact with exhibition swine; often, the cases are in swine exhibitors with close and prolonged swine exposure. The concurrent detection of genetically identical influenza $\mathrm{A}$ viruses from exhibition swine across 2 states illustrates the rapidity with which this virus, and potentially other pathogens, can move within the highly mobile exhibition swine population. In addition to the zoonotic risks of influenza A virus, this pattern serves as a warning of possible dissemination of other emerging or high-consequence diseases in swine. Management practices common in the exhibition swine industry (i.e., frequent exhibition and relaxed biosecurity) facilitate the rapid dissemination of influenza virus across a large geographic landscape (14). Collaboration between animal and public health officials facilitated this investigation. Methods to control intraspecies and interspecies influenza virus transmission during swine shows have been outlined by the National Association of State Public Health Veterinarians (http://nasphv.org/Documents/Influenza_Transmission_ at_Swine_Exhibitions_2016.pdf).

The recovery of human-like H3 influenza A viruses from exhibition swine supports previous studies demonstrating that the US commercial swine herd can serve as an influenza A reservoir for the much smaller exhibition swine population, which is more accessible to humans. Within the US commercial herd, the proportion of $\mathrm{H} 3$ isolates containing human-like $\mathrm{H} 3$ nearly doubled to $46 \%$ in spring and summer 2016 (data not shown). Whereas human-like H3s have been circulating, reassorting, and becoming more prevalent in the commercial swine population since 2012, introduction and expansion of the human-like $\mathrm{H} 3$ reassortant influenza A viruses in exhibition swine facilitated documented zoonoses from this genotype. The path traversed by this human-like $\mathrm{H} 3$, from initial introduction from humans to swine until the zoonotic transmission events of 2016, demonstrates how novel viruses can be generated and maintained in animal populations and, subsequently, can infect humans through specific ecologic niches like swine exhibitions or live-animal markets (15). Therefore, continued surveillance in swine populations is imperative for detecting novel influenza A viruses that threaten swine and human health. 


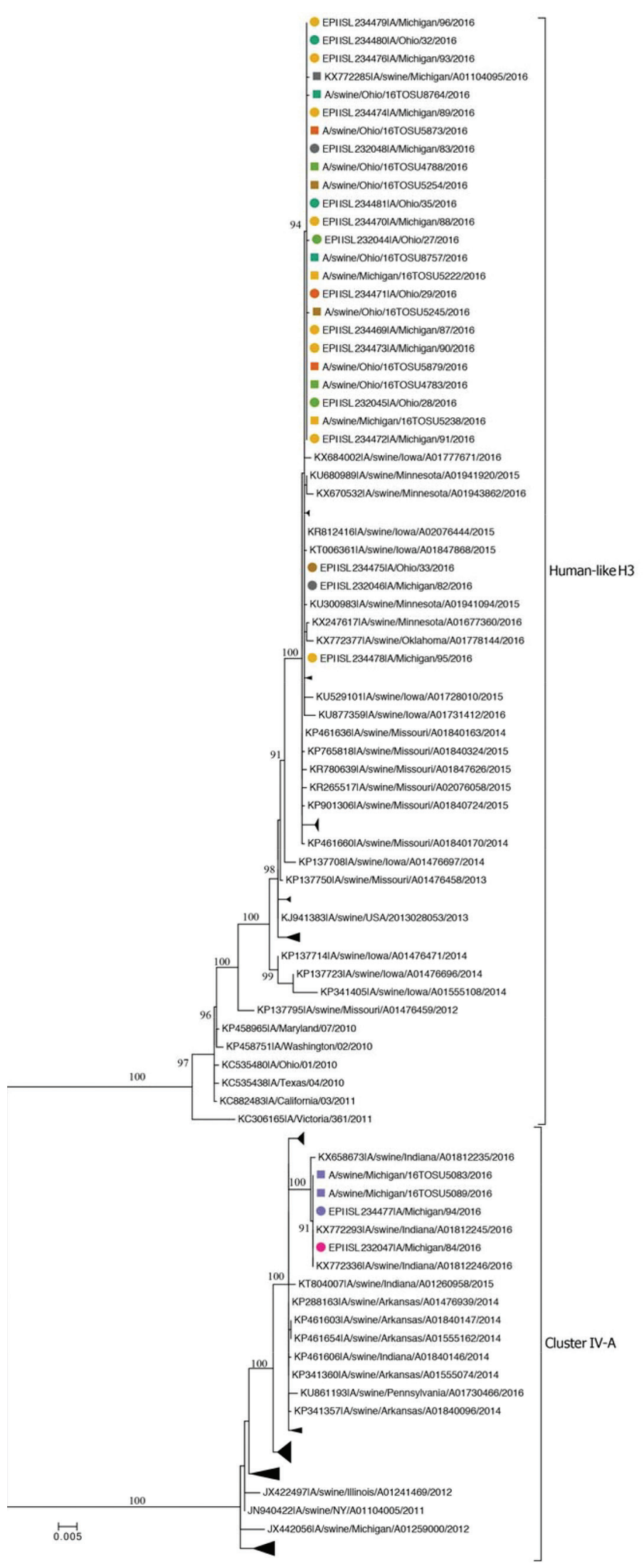

Figure 1. Phylogenetic relationships inferred for subtype $\mathrm{H} 3$ hemagglutinin genes of 2 distinct lineages (indicated on the right of the tree) from influenza $A$ viruses isolated from swine and humans at agricultural fairs in Ohio and Michigan, USA, 2016. Isolates recovered are shown as squares for swine and circles for humans; colors indicate the fair attended. Scale bar indicates nucleotide substitutions per site; collapsed clades within each lineage are monophyletic clades of swine $\mathrm{H} 3 \mathrm{HA}$ genes. 
Table 2. H3N2 genotypes identified in influenza A viruses detected in exhibition swine at agricultural fairs associated with 16 human variant H3N2 cases, Michigan and Ohio, USA, 2016*

\begin{tabular}{|c|c|c|c|c|c|c|c|c|}
\hline Genotype & PB2 & PB1 & PA & $\mathrm{HA}$ & NP & NA & $\mathrm{M}$ & NS \\
\hline H3 genotype $1, n=2$ & trig & trig & trig & Swine cluster IV-A & trig & 2002 & $\mathrm{pdm}$ & trig \\
\hline Human-like H3, $n=11$ & trig & trig & trig & Human-like H3 & trig & 2002 & $\mathrm{pdm}$ & Trig \\
\hline
\end{tabular}

*Genomic constellations of 13 influenza A virus isolates from swine are organized by the 8 gene segments of the influenza A virus genome with HA categorized as derived from the 2010-11 human seasonal H3N2 virus (human-like H3) or the established swine lineage H3N2 (cluster IV-A). The 6 internal gene segments (PB2, PB1, PA, NP, M, NS) are classified as originating from either the 1998 triple-reassortant internal gene (trig) or influenza A(H1N1)pdm09 (pdm). All NA genes were descendants of the 2002 N2 lineage common among North American swine (12). HA, hemagglutinin; M, matrix; NA, neuraminidase; NP, nucleoprotein; NS, nonstructural protein; PA, polymerase acidic; PB, polymerase basic.

\section{Acknowledgments}

We thank the agricultural fairs for participating, along with Alicia Janas-Martindale, Lauren Smith, and Amy Albers.

This work was funded with federal funds from the Centers of Excellence for Influenza Research and Surveillance, National Institute of Allergy and Infectious Diseases, National Institutes of Health, and Department of Health and Human
Services, under contract nos. HHSN272201400006C and HHSN272201400008C. R.R.W. and T.K.A. were funded by the US Department of Agriculture Agricultural Research Service (USDA-ARS) Specific Cooperative Agreement no. 58-3625-4-070 and by an appointment to the USDA-ARS Research Participation Program administered by the Oak Ridge Institute for Science and Education through an interagency

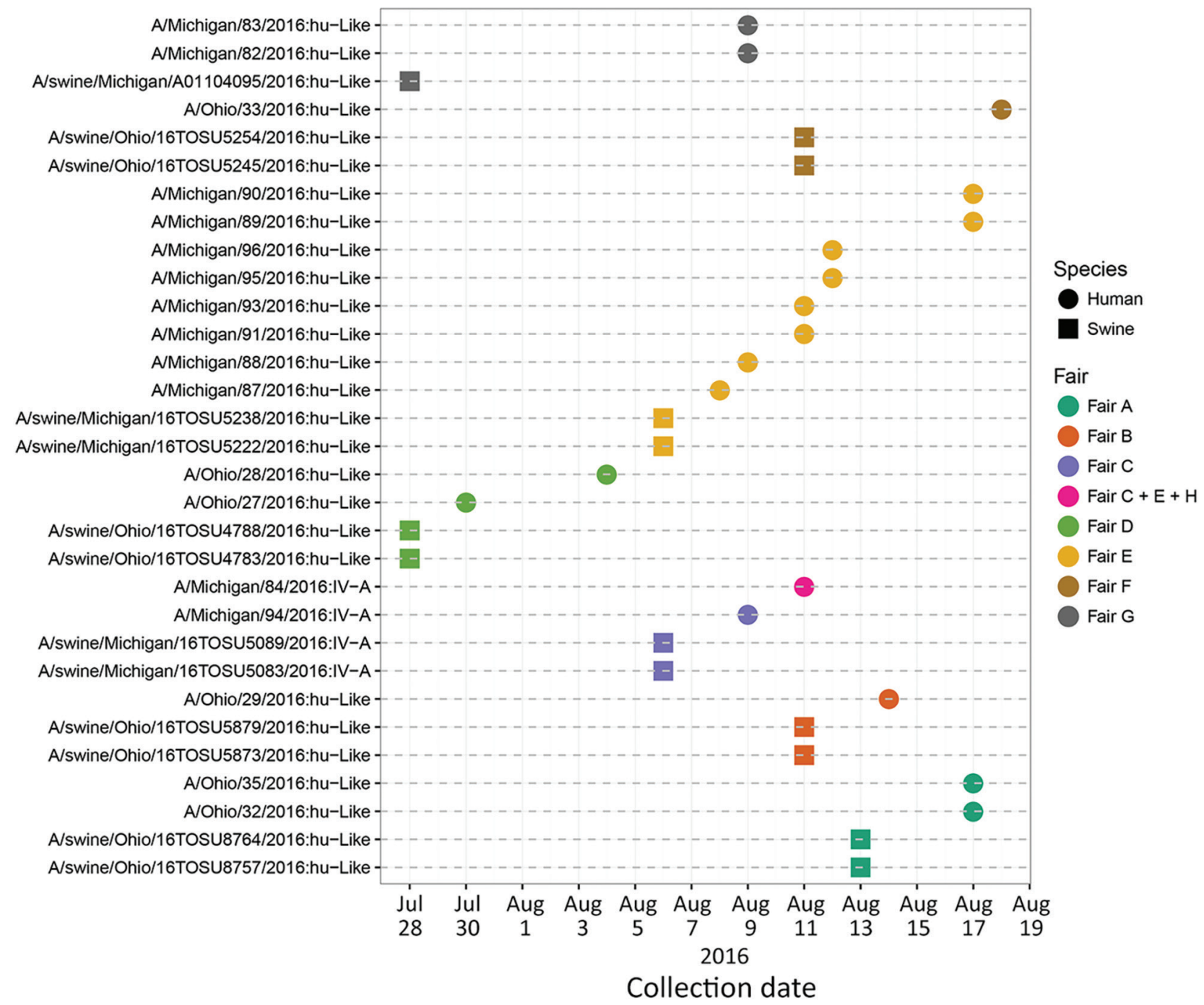

Figure 2. Timeline of detection of human and swine influenza A virus isolates at agricultural fairs in 2016. Isolates recovered are shown as squares for swine and circles for humans; colors indicate the fair attended. One person was exposed to pigs at 3 fairs (C, E, and $\mathrm{H}$ ). Fair $\mathrm{H}$ is an eighth location not described in this study. 
agreement between the US Department of Energy and USDA under contract number DE-AC05-06OR23100.

The findings and conclusions in this report are those of the authors and do not necessarily represent the views of USDA Animal and Plant Health Inspection Service, USDA-ARS, the Centers for Disease Control and Prevention, or the Agency for Toxic Substances and Disease Registry. USDA is an equal opportunity provider and employer.

Dr. Bowman is an assistant professor at The Ohio State University, where he leads a team researching the ecology and epidemiology of influenza A virus in swine and avian populations. He and his team are working to control influenza A virus in swine populations and reduce influenza A virus transmission across the swine-human interface.

\section{References}

1. Jhung MA, Epperson S, Biggerstaff M, Allen D, Balish A, Barnes N, et al. Outbreak of variant influenza $\mathrm{A}(\mathrm{H} 3 \mathrm{~N} 2)$ virus in the United States. Clin Infect Dis. 2013;57:1703-12. http://dx.doi.org/10.1093/cid/cit649

2. Schicker RS, Rossow J, Eckel S, Fisher N, Bidol S, Tatham L, et al. Outbreak of influenza A(H3N2) Variant virus infections among persons attending agricultural fairs housing infected swine-Michigan and Ohio, July-August 2016. MMWR Morb Mortal Wkly Rep. 2016;65:1157-60. http://dx.doi.org/10.15585/ mmwr.mm6542a1

3. Bowman AS, Nolting JM, Nelson SW, Slemons RD. Subclinical influenza virus A infections in pigs exhibited at agricultural fairs, Ohio, USA, 2009-2011. Emerg Infect Dis. 2012;18:1945-50. http://dx.doi.org/10.3201/eid1812.121116

4. Nolting JM, Szablewski CM, Edwards JL, Nelson SW, Bowman AS. Nasal wipes for influenza A virus detection and isolation from swine. J Vis Exp. 2015;(106):e53313.

5. Edwards JL, Nelson SW, Workman JD, Slemons RD, Szablewski CM, Nolting JM, et al. Utility of snout wipe samples for influenza A virus surveillance in exhibition swine populations. Influenza Other Respi Viruses. 2014;8:574-9. http://dx.doi.org/10.1111/irv.12270

6. Bowman AS, Nelson SW, Page SL, Nolting JM, Killian ML, Sreevatsan S, et al. Swine-to-human transmission of influenza
A(H3N2) virus at agricultural fairs, Ohio, USA, 2012. Emerg Infect Dis. 2014;20:1472-80. http://dx.doi.org/10.3201/eid2009.131082

7. Bowman AS, Sreevatsan S, Killian ML, Page SL, Nelson SW, Nolting JM, et al. Molecular evidence for interspecies transmission of $\mathrm{H} 3 \mathrm{~N} 2 \mathrm{pM} / \mathrm{H} 3 \mathrm{~N} 2 \mathrm{v}$ influenza A viruses at an Ohio agricultural fair, July 2012. Emerg Microbes Infect. 2012;1:e33. http://dx.doi.org/10.1038/emi.2012.33

8. Katoh K, Standley DM. MAFFT multiple sequence alignment software version 7: improvements in performance and usability. Mol Biol Evol. 2013;30:772-80. http://dx.doi.org/10.1093/molbev/ mst010

9. Kumar S, Stecher G, Tamura K. MEGA7: Molecular Evolutionary Genetics Analysis version 7.0 for bigger datasets. Mol Biol Evol. 2016;33:1870-4. http://dx.doi.org/10.1093/molbev/msw054

10. Nguyen LT, Schmidt HA, von Haeseler A, Minh BQ. IQ-TREE: a fast and effective stochastic algorithm for estimating maximumlikelihood phylogenies. Mol Biol Evol. 2015;32:268-74. http://dx.doi.org/10.1093/molbev/msu300

11. Minh BQ, Nguyen MA, von Haeseler A. Ultrafast approximation for phylogenetic bootstrap. Mol Biol Evol. 2013;30:1188-95. http://dx.doi.org/10.1093/molbev/mst024

12. Kitikoon P, Nelson MI, Killian ML, Anderson TK, Koster L, Culhane MR, et al. Genotype patterns of contemporary reassorted H3N2 virus in US swine. J Gen Virol. 2013;94:1236-41. http://dx.doi.org/10.1099/vir.0.051839-0

13. Rajão DS, Gauger PC, Anderson TK, Lewis NS, Abente EJ, Killian ML, et al. Novel reassortant human-like H3N2 and H3N1 influenza A viruses detected in pigs are virulent and antigenically distinct from swine viruses endemic to the United States. J Virol. 2015;89:11213-22. http://dx.doi.org/10.1128/JVI.01675-15

14. Nelson MI, Stucker KM, Schobel SA, Trovão NS, Das SR, Dugan VG, et al. Introduction, evolution, and dissemination of influenza A viruses in exhibition swine in the United States during 2009 to 2013. J Virol. 2016;90:10963-71. http://dx.doi.org/10.1128/JVI.01457-16

15. Choi MJ, Torremorell M, Bender JB, Smith K, Boxrud D, Ertl JR, et al. Live animal markets in Minnesota: a potential source for emergence of novel influenza A Viruses and interspecies transmission. Clin Infect Dis. 2015;61:1355-62. http://dx.doi.org/10.1093/cid/civ618

Address for correspondence: Andrew S. Bowman, The Ohio State University, Department of Veterinary Preventive Medicine, 1920 Coffey Rd, Columbus, OH 4310, USA; email: bowman.214@osu.edu 